\title{
Resenhas
}

\section{Educação e instrução nas províncias e na Corte Imperial (Brasil, 1822-1889)}

Autor: José Gonçalves Gondra

Cidade: Vitória - ES

Editora: EDUFES

Ano: 2011

As dificuldades da compreensão histórica do que foi a educação no Império brasileiro são muitas e vão desde o trabalho cotidiano nos acervos públicos e as dificuldades de acesso à documentação até a sofisticada crítica da memória, constituída posteriormente, que o tema exige. É verdade que atualmente a tradição historiográfica republicana, que produziu o enorme vazio a respeito da educação organizada e mantida durante o Império no Brasil, foi superada por um sistematizado esforço de pesquisa e análise. A articulação de grupos de pesquisadores, em torno do período em eventos, como os Seminários de Fontes para a Pesquisa em História da Educação do Século XIX, e a publicação das conclusões de estudos sobre o oitocentos brasileiro vêm mostrando, há mais de uma década e com muita intensidade, que a educação brasileira oitocentista é um período fértil tanto para a problematização de questões atuais do campo educacional quanto da produção historiográfica.

No entanto, ainda há bastante o que fazer, conforme atesta o livro Educação e instrução nas províncias e na Corte Imperial (Brasil, 1822-1889). O mais recente esforço para pensar a educação e a instrução nas províncias e na Corte é a obra organizada por José Gonçalves Gondra e Omar Schneider, que reúne, em 15 artigos, uma plêiade de 23 especialistas no estudo da educação no tempo do Império, com o objetivo de "[...] visibilizar as experiências em termos de educação e instrução desenvolvidas na complexa malha provincial e na Capital do Império [...]" (p. 13). Trata-se do terceiro volume da coleção Horizontes da Pesquisa em História da Educação no Brasil, iniciativa da editora da Universidade Federal do Espírito Santo e da Sociedade Brasileira de História da Educação. Embora o título delimite o período 1822-1889 como recorte, e a proposta de organização dos capítulos tenha se efetivado em função da abrangência das iniciativas regionais então projetadas e 
desenvolvidas, as histórias que este livro traz não se prendem aos limites da história institucional e político-administrativa.

As orientações diversas da escrita e a própria diversidade dos autores preservam uma pluralidade de perspectivas que contribui para a compreensão das possibilidades de análise hoje presentes na historiografia. Entre outros, estão presentes investimentos de pesquisa sobre a educação dos índios amansados, sobre o uso dos métodos, dos espaços e dos tempos escolares e acerca das estratégias populares de educação ou de resistência ao modelo oficial de instrução. Cotejar esses diferentes interesses revela um importante trabalho com as categorias da análise histórica. Sob esse aspecto, perpassam o livro desde abordagens ancoradas na utilização de categorias como cultura escolar e forma escolar até a elaboração de instrumentos de análise muito próprios como o de processo escolarizador.

Outra chave de entrada para a leitura é o escopo dos textos. Nos estudos que estão reunidos em Educação e instrução nas províncias e na Corte Imperial, há, por um lado, o esforço de síntese e interpretação e, por outro, a organização de inventários empenhados na discussão historiográfica da pesquisa acerca da educação no período. Sobretudo nos textos em que predomina o primeiro tipo de expediente, é possível acompanhar a construção de quadros compreensivos capazes de mostrar os principais resultados das iniciativas educacionais dos governos provinciais. Para as províncias do Amazonas e Pará, Ceará e Rio Grande do Norte, Paraíba e Pernambuco, Sergipe, Bahia, Espírito Santo, Minas Gerais e Rio Grande do Sul, os autores indicam formas de abordar o processo de escolarização das suas sociedades e, principalmente, tecem relações entre o político e o cultural. De outro tipo é o entendimento que os mapeamentos da produção permitem ter. O levantamento dos estudos a respeito da história da educação no Maranhão e Piauí, no Rio de Janeiro, no Paraná, em Alagoas, em Goiás e Mato Grosso, e em Santa Catarina informa sobre a profusão dos objetos de pesquisa e dos meios de análise que vem sendo utilizada no trabalho com o oitocentos brasileiro. Por se tratar de uma diferença de ênfase e não de uma opção entre um expediente e outro, os 15 artigos reunidos neste livro auxiliam na tarefa de compreensão histórica, senão das realizações dos governos provinciais e da Corte, ao menos dos mecanismos explicativos que lhes indiciam as interpretações possíveis. Dessa perspectiva, o texto escrito por Maria Lucia Hilsdorf acerca de São Paulo é exemplar.

Mesmo que, de fato, se beneficie dos diferentes interesses de pesquisa e da pluralidade das perspectivas de análise dos seus autores, Educação e instrução nas províncias e na Corte Imperial é daqueles casos 
raros de coletânea cuja força está no conjunto, no arranjo obtido pelo livro. Conforme os organizadores esclarecem no prefácio, solicitou-se aos autores que procurassem contemplar a bibliografia existente sobre educação na região, mapear o tipo de documentação disponível e pensar as perspectivas e desafios para a pesquisa em história da educação e instrução nas províncias e na Corte. Outra orientação geral do livro foi observar o emprego dos termos educação e instrução à época. Considerando que, então, a distinção entre as ações sobre os variados aspectos da conduta dos sujeitos sociais e as medidas voltadas para organizar e legitimar a escola na sociedade brasileira pautaram o debate acerca das modalidades de intervenção educativa, sugeriu-se rever e observar o uso dos termos educação e instrução na literatura pedagógica do período. O resultado conseguido, efetivamente, contribui para melhor entendimento da organização do ensino nas províncias e na Corte Imperial e das premissas teórico-metodológicas da sua historiografia. Uma leitura transversal, articulada e integrada, das contribuições que o volume colige mostra-o bem, sobretudo nos quatro pontos indicados pelos organizadores.

Primeiro, a varredura que os artigos realizaram da bibliografia acerca da educação nas províncias e na Corte mostra um importante acúmulo de reflexões. Trata-se de obras que são já clássicos de referência, como nos casos do que José Veríssimo, José Ricardo Pires de Almeida e Primitivo Moacyr publicaram. Há, igualmente, um conjunto de obras que, provenientes do campo da história, tornaram-se referência fundamental para o trabalho com a história da educação, como O Tempo Saquarema de Ilmar Rhollof de Mattos e os trabalhos de Sidney Chalhoub e Eni de Mesquita Samara. No campo específico da história da educação, as produções de, por exemplo, Oscar Thompson, Archimiro Mattos, J. L. Rodrigues, João Craveiro Costa, José Calasans, J. B. Mello, José Mendonça e Abelardo Duarte constituem referências significativas para a historiografia das províncias. Principalmente, chama atenção a profusão das novas produções. Maria Stephanou, Maria Helena Câmara Bastos, Elomar Tambara, Luciano Mendes de Faria Filho, Heloisa Villela e Tarcísio Mauro Vago são nomes que, na última década e meia, vêm consolidando a pesquisa sobre a educação oitocentista com suas publicações. Seus estudos são amplamente referenciados nos artigos editados nesta compilação. Também as teses e dissertações elaboradas nos programas de pós-graduação das universidades de diferentes estados brasileiros vão contribuindo com novas perspectivas de estudo. Nesse aspecto, o levantamento realizado da produção aponta que, de Norte a Sul, há trabalhos representativos da renovação dos estudos sobre o Império. Além da rede de referências 
que articulam, é relevante dizer que as contribuições reunidas neste volume foram produzidas por autores que igualmente têm publicado trabalhos fundamentais para o entendimento da história da educação oitocentista. Junto aos organizadores, José Gonçalves Gondra e Omar Schneider, colaboraram Adriana Feitosa, Adriana Maria Paulo da Silva, Alessandra Schueler, Berenice Corsetti, César Augusto Castro, Cynthia Greive Veiga, Elizabeth Siqueira, Fátima Neves, Ione de Souza, Irma Rizzini, José Carlos Silva, Leonete Schmidt, Maria das Graças Loiola, Maria Lucia Hilsdorf, Mauricéia Ananias, Samuel Castellanos, Sandra de Abreu, Sônia Maria Araújo e Terciane Luchese.

Depois, o mapeamento das fontes disponíveis para pensar a educação nas províncias e na Corte Imperial esclarece acerca dos caminhos da pesquisa histórica a respeito da escola oitocentista. Sob esse aspecto, Educação e instrução nas províncias e na Corte Imperial constitui um testemunho do quanto têm sido diversificadas as estratégias dos historiadores para definir seus objetos de pesquisa. Todo seu conjunto repõe a profícua discussão sobre as fontes da história da educação que, da última década e meia para cá, orientou grande parte da renovação historiográfica no país. Por um lado, a cuidadosa lembrança dos limites impostos pelas fontes ditas oficiais, como o são os relatórios das inspetorias provinciais e suas comissões, as estatísticas e recenseamentos, as atas e a legislação, não deixa esquecer a necessária crítica das fontes. Por outro lado, acompanha a reflexão sobre o uso de outros tipos de documentação a necessária crítica dos métodos e das categorias de análise empregadas. Assim, mostra-se que o trabalho com impressos, inventários, prestação de contas, listas de compra e de despesas com educação, livros, utensílios e boletins escolares, cartões-postais, fotografias, abaixo-assinados, anais de congresso, entre tantas mais, não tem renovado apenas os temas de pesquisa e sua abordagem, mas a própria elaboração metodológica que a interpretação dessas fontes implica.

Há também a preocupação com as possibilidades e limites da pesquisa sobre os processos de escolarização durante o Império e os desafios que atualmente se impõem aos profissionais deste canteiro da história da educação. A varredura da bibliografia e o mapeamento das fontes que resultam do trabalho realizado para a composição do livro Educação e instrução nas províncias e na Corte Imperial delineiam-se numa espécie de estado da arte da investigação sobre os processos de escolarização do Brasil oitocentista. $\mathrm{O}$ avanço sobre os limites impostos pela historiografia produzida pelos renovadores escolanovistas e por uma certa história das ideias pedagógicas fica marcado tanto pela abrangência e natureza 
das fontes mobilizadas nas análises, quanto pela prática insistente da crítica historiográfica. No entanto, outras lacunas aparecem e, conforme orientação dos organizadores, são consideradas pelos autores. Não obstante a especificidade dos interesses e das expectativas de pesquisa em cada região, há preocupações muito gerais e indicativas dos espaços para a inovação. É recorrente, por exemplo, a constatação de que ainda se sabe pouco sobre a cultura material das escolas oitocentistas, compreendese mal a história das redes de ensino constituídas fora das capitais e de que o conhecimento histórico sobre os processos de educação não formais continua precário. De outra parte, a pesquisa sobre a educação e os processos de aprendizagem entre escravos e libertos, as questões relativas aos povos indígenas, as dinâmicas educativas instituídas pelo viés do gênero, da etnia e da geração são igualmente campos ainda pouco lavrados. Também é significativo o número de relações que, segundo os autores, demandam investimento. Precisamente nesse sentido, reconhece-se o pouco que foi feito para se compreender, por exemplo, as relações entre as práticas prescritas e a atuação dos agentes do processo de escolarização; as táticas das populações consideradas escolarizáveis e as estratégias governamentais; a escolarização, a maçonaria e o ensino laico; e as relações das famílias e tutores com a questão da formação.

Finalmente, quarto ponto. A concepção do período em que a educação era um importante instrumento civilizador e a escola seu principal veículo se impõe às principais conclusões das pesquisas. Mesmo diante dos reduzidos números de atendimento escolar, foi por um hábil discurso acerca da educação que se procurou "superar a selvageria pela civilização" (p. 18), articular uma "estratégia civilizadora do povo" (p. 272) ou "promover os progressos civilizadores, materiais e políticos" (p. 446) da nação. E não só nos resultados, os estudos reunidos neste $3^{\circ}$ volume da coleção Horizontes da Pesquisa em História da Educação expressam essa compreensão da época, a respeito das medidas tomadas para organizar as escolas e das ações efetuadas sobre a conduta de diferentes sujeitos sociais. Igualmente, os protocolos de leitura construídos pelos autores exploram o caráter civilizatório que então se queria dar à educação pública. A ênfase das análises nas iniciativas do poder público mostram sobretudo que a escola foi uma instituição constituída, justificada e disseminada no Brasil-Império como signo de civilização e progresso. Nesse sentido, além de delinear uma espécie de estado da arte da produção sobre a educação do período e apontar as ainda importantes lacunas da pesquisa, o livro organizado por Gondra e Schneider permite uma revisão das interpretações sobre as realizações da escola oitocentista no país. Trata-se, assim, de um livro 
útil tanto pelas referências de pesquisa e possibilidades de trabalho que sistematiza quanto pelas leituras que propõe.

A proposta deste volume determinou tarefas gerais a respeito do estudo da história da educação nas províncias e na Corte, que fizeram as análises individuais convergirem em pelo menos outros quatro aspectos. Por um lado, o trabalho de varredura e mapeamento se completa com a identificação dos grupos de pesquisa que atuam no estudo da educação no Império e dos arquivos e acervos que têm sido frequentados. Por outro, na reflexão sobre a história e a historiografia da educação à época, são insistentes a discussão da obra de Primitivo Moacyr e as preocupações com a distância entre o proclamado e prescrito em relação ao vivido e realizado. Assim, primeiro aspecto, o conjunto dos artigos compilados mostra uma rede de grupos de estudo e pesquisa, que indica a importância do trabalho coletivo na consolidação de um campo de investigação. Os relatos apontam que a atuação de pesquisadores vinculados ao GHIMEM/ MA, NEDHEL/MA, NEPHEPE/UFPE, GHENO/UFPB, HISTEDBR, CEDU/UFAL, GEPHE/UFMG, NEPHE/UERJ e GEM/UFMT, por exemplo, vem constituindo pontos de apoio e oportunidade de formação imprescindíveis para a consecução de investigações mais abrangentes e com capacidade comparativa. Decorre desse trabalho conjunto, um segundo aspecto das pesquisas sobre a educação oitocentista que os estudos demarcam com firmeza, o trabalho nos arquivos públicos estaduais. Os arquivos públicos de praticamente todos os estados do país são lembrados e têm uma parte do seu acervo analisada pelos autores. Terceiro aspecto: a obra de Primitivo Moacyr é presença marcante na análise de muitos dos artigos publicados neste livro. A compilação de fontes que ele produziu e as análises que articulou, num esforço de compreensão das iniciativas públicas na área da educação entre 1834 e 1889, são consideradas e discutidas em diferentes momentos e a propósito de diferentes províncias. Sobretudo, compreende-se, de diversas perspectivas, que as interpretações de Primitivo Moacyr precisam ser matizadas quando se quer analisar não só a história da educação no Império, mas também os programas a partir dos quais sua historiografia foi construída.

A respeito das preocupações com a sempre distante relação entre o prescrito e o realizado na educação brasileira, verificada em boa parte dos autores que colaboraram para as muitas realizações do livro Educação e instrução nas províncias e na Corte Imperial, um último comentário. Essa grade de leitura acerca da instrução do oitocentos é o que me pareceu mais próximo dos instrumentos de interpretação de uma história vista do centro, institucional e político-administrativa, presente no livro. Pretender compreender o alcance das iniciativas do poder público e as alterações nas práticas educativas a partir da análise da legislação, dos discursos 
da prática legislativa e de toda a série de documentos administrativos é operação que continua produzindo resultados. Ao lado do estudo das práticas e instituições da educação nas províncias e na Corte Imperial, o trabalho de reexame e de reescrita da história da educação daquele período atualmente em andamento, e de que este livro é um testemunho, tem sido feito em meio à abordagem desse tipo de documentação. No entanto, o trabalho com esse tipo de fonte não impede a elaboração de outras operações de leitura e interpretação. Nesse sentido e a título de exemplo, a reflexão acerca da relação que os vários grupos sociais que frequentavam a escola mantinham com seu funcionamento e com os mecanismos que aí estavam à disposição, ou sobre os que lhe resistiam, também visibiliza elementos tão fundamentais da situação concreta do fazer ordinário da escola, quanto os que foram manejados sob as vistas das instâncias do poder administrativo. Uma vez mais se trata de evitar a produção de um vazio, agora a respeito das tensões que se estabelecem na sociedade entre as suas várias instituições, entre diferentes grupos sociais e entre os múltiplos sujeitos que vivenciaram o cotidiano escolar.

No momento mesmo em que é revista, a história da educação e da escola oitocentista recebe, com a publicação de Educação e instrução nas províncias e na Corte Imperial, um tipo de contribuição que é característica dos períodos de reformulação dos problemas de pesquisa. Ao mesmo tempo em que insiste nos estados da arte e balanços, pratica modelos híbridos de compreensão dos objetos de investigação e sugere novos protocolos de análise e crítica.

André Luiz Paulilo

Professor na Faculdade de Educação Universidade Estadual de Campinas

Endereço para correspondência: Faculdade de Educação/Universidade Estadual de Campinas Rua Bertrand Russel, 801 Cidade Universitária Zeferino Vaz Campinas - SP

CEP: $13083-865$

E-mail:paulilo@unicamp.br

Recebido em: 28 abr. 2011 Aprovado em: 17 out. 2011 
